\title{
As parteiras, o partejar e a noção de pessoa em Ribeira da Barca, Cabo Verde
}

\author{
Midwives, midwifery and the notion of person \\ in Ribeira da Barca, Cabo Verde
}

\author{
Carmem Helena Carvalho Cruz* \\ Miriam Steffen Vieira**
}

\begin{abstract}
Resumo: Este estudo sobre as parteiras, o partejar e a noção de pessoa em Ribeira da Barca visa analisar como as técnicas utilizadas no parto se relacionam com a constituição da pessoa. Essa reflexão passa necessariamente por uma discussão da noção de pessoa como indivíduo total, onde não existe uma fronteira visível entre a natureza e a cultura. Essa forma como se constrói a noção de pessoa é verificável na maneira como se molda o corpo na gravidez, no parto e no pós-parto. Neste estudo é usado o método etnográfico de pesquisa pela ênfase conferida às práticas sociais. Nessa ótica, é analisada como se dá forma ao corpo, partindo do princípio que este é passível de ser moldado, dinâmico e com fluxos vitais, integrado nos ciclos da vida e do ambiente (onde não existe uma fronteira visível entre natureza e cultura). É importante concluir que em Ribeira da Barca a pessoa é relacional, que se dá através da relação com os outros e consigo mesma.
\end{abstract}

Palavras-chave: Parto. Parteiras. Partejar. Noção de pessoa.

Abstract: This study of midwives, midwifery and the concept of person in Ribeira da Barca aims to analyze how the techniques used in childbirth determine how one does constitute the notion of a person. This reflection necessarily involves a discussion of the notion of the person as a whole individual, where there is no visible boundary between nature and culture. How the notion of person is build is verifiable in the way the body is shaped during pregnancy, childbirth and postpartum. This article it was used the ethnographic research method by the focus in social practices. Accordingly, the forming the body is analyzed, assuming this is something which can be molded,

* Mestre em Ciências Sociais pela Universidade de Cabo Verde, Licenciada em Ciências da Comunicação pela Universidade da Beira Interior, Covilhã-Portugal.<Carmem.Cruz@ine.gov.cv>.

** Doutora em Antropologia Social pela Universidade Federal do Rio Grande do Sul (Ufrgs, Porto Alegre, RS, Brasil), professora do PPG em Ciências Sociais da Unisinos em São Leopoldo, RS, Brasil, e professora colaboradora do PPG em Ciências Sociais da Universidade de Cabo Verde <miriamsteffen@gmail.com>. 
dynamic and vital flows, integrated in the cycles of life and the environment (where there is no visible boundary between nature and culture). It is important to conclude that in Ribeira da Barca one is relational, occurs within a relationship with others and with oneself.

Keywords: Parturition. Midwife. Midwifery. Notion of person

\section{Introdução}

A primeira vez que acompanhou a tia, disse que sentiu medo porque lhe mandava fazer coisas como "cortar o umbigo", ela não sabia como fazer, e a tia lhe ordenava "faça" e depois "banha a criança". (D. Mira, Parteira)

Este estudo está limitado à realidade cabo-verdiana, especificamente à localidade de Ribeira Barca, pertencente ao Município de Santa Catarina, localizado no interior da Ilha de Santiago. Com este estudo, pretendeu-se conhecer as práticas e valores relacionados com a gestação, o parto e a sua relação com a conceção de pessoa em Ribeira da Barca.

Cabo Verde é um arquipélago constituído por dez ilhas, sendo nove habitadas, com uma superfície de $4.033 \mathrm{~km}$ e uma população de 491.683 habitantes, e fica situado na costa ocidental da África, a $1040 \mathrm{~km}$ do Senegal.

Santa Catarina é um dos nove municípios da Ilha de Santiago, sendo Ribeira da Barca uma vila pertencente a este município. Segundo os dados do Recenseamento Geral da População e Habitação de 2010, realizado pelo Instituto Nacional de Estatística, Ribeira da Barca é a segunda localidade deste município em termos populacionais. Depois da Cidade de Assomada, é a que tem mais habitantes (2.317), sendo 1.115 indivíduos do sexo masculino e 1.202 do sexo feminino, estando a maioria em idade reprodutiva (627 mulheres de 15 a 49 anos e 633 homens de 15 a 59 anos). Ribeira da Barca é uma zona piscatória onde a população vive essencialmente da pesca e da apanha de areia. ${ }^{1}$

Em Santa Catarina existe um hospital regional para o Norte da Ilha de Santiago, dois centros de saúde, quatro postos sanitários e nove unidades sanitárias de base, sendo que, na presente data, apenas cinco estão em funcionamento. Na comunidade de Ribeira da Barca existe apenas um posto sanitário e um enfermeiro permanente que faz controle das grávidas,

\footnotetext{
${ }^{1}$ Apanha de areia refere-se à extração de inertes para a construção civil. Esta atividade é realizada essencialmente por mulheres e seus filhos.
} 
planejamento familiar, pequenos curativos, visitas domiciliares a crianças, grávidas e velhos etc. É disponibilizado um médico clínico geral para consultas mensais nesse posto. Os partos e os casos mais delicados são encaminhados ao Hospital Regional de Santiago Norte, em Santa Catarina, que fica acerca de $12 \mathrm{~km}$ de Ribeira da Barca.

Nas zonas rurais a cobertura dos serviços de saúde é muito fraca, onde a maioria dos partos é realizada nos domicílios, não obstante as intensas campanhas de sensibilização, realizadas pelo Ministério da Saúde, no sentido de os partos serem realizados nos serviços de saúde. Também, a procura por parteiras tradicionais é frequente e transmitida intergeracional. Como se verá adiante, as mulheres em trabalho de parto se sentem mais seguras por terem, por perto, uma conhecida e de confiança, que pode ser sua vizinha, comadre, tia e, em certos casos, a própria mãe.

Conforme a percepção exploratória, na localidade de Ribeira da Barca, durante a gestação, a mulher é cuidada sobretudo pela família materna, em que é rodeada de atenção, de cuidados com a alimentação, com a sua saúde, mas que, no entanto, continua exercendo a sua tarefa doméstica e permanecendo no seu trabalho. Essa envolvência da mulher acontece, também, durante o parto, em que ela é assistida pela mãe, parteira, enfermeira, etc.

Para conhecer essa vivência que é própria do quotidiano, utilizei o método etnográfico pela ênfase conferida às práticas sociais e à produção de significados desde a perspetiva nativa (Malinowski, 1978; Geertz, 1989).

Segundo DaMatta (1981) o fazer etnográfico possibilita a experiência do "estranhamento" em relação aos valores e conceções de mundo que, por fazerem parte do nosso dia-a-dia, são naturalizados e passam despercebidos. Enquanto cabo-verdiana que vive neste contexto, trata-se do desafio de "estranhar" o familiar e colocar em perspectiva todos os conhecimentos e informações, sem privilegiar aqueles me que causam admiração ou estranheza em detrimento dos fatos comuns e rotineiros.

Na perspectiva de Favret-Saada (2005) seria mais do que transformar o exótico em familiar, mas deixar-se afetar pelas mesmas sensibilidades que afetam o nativo. Sentir-se afetado, refere o autor, não tem nada a ver com o que se designa como empatia:

ocupar tal lugar afeta-me, quer dizer, mobiliza ou modifica meu próprio estoque de imagens, sem contudo instruir-me sobre aquele dos meus parceiros. [...] o próprio fato de que aceito ocupar esse lugar e ser afetado por ele abre uma comunicação específica com os nativos: uma comunicação sempre involuntária e desprovida de intencionalidade, e que pode ser verbal ou não. (Favret-Saada, 2005, p. 159) 
Neste sentido, ainda segundo Favret-Saada, os acontecimentos devem atingir em pleno a pesquisadora, não da mesma forma que atinge os nativos, mas talvez com a mesma intensidade - ensinamento que procurei seguir nesta etnografia sobre parteiras, o partejar e a noção de pessoa numa região do interior da ilha de Santiago - Ribeira da Barca.

Em Ribeira da Barca existem seis parteiras tradicionais. Foram entrevistadas e acompanhadas, de forma intensiva, durante três meses, de julho a outubro de 2012, mas este artigo se refere, apenas, à experiência de três delas, porque atuam com mais frequência e são as mais chamadas na comunidade para realizarem os partos.

Entrei em contacto com essas parteiras através da agente sanitária do posto de saúde de Ribeira da Barca que as conhecem. Fui muito bem acolhida por todas elas que, desde o início, demonstraram total disponibilidade em participar deste estudo. Essas parteiras são senhoras domésticas, mães, com idade compreendida entre 50 e 88 anos, que trabalham no cultivo de pequenas parcelas de terreno ao redor das suas casas, na época das chuvas. Todas têm o $4^{\circ}$ ano de escolaridade, que corresponde a quarta classe antiga.

$\mathrm{O}$ que foi mais desafiador foi o fato de viver neste contexto e de ter a necessidade, como referido anteriormente, de um "estranhamento" em relação àquilo que me era familiar e sentir-me afetada por ela.

Durante o trabalho de campo foi utilizado o diário de campo, onde todas observações foram anotadas. Foram, também, realizadas entrevistas utilizando técnicas de entrevista informal ou semiestruturada, e algumas foram gravadas e outras apenas anotadas.

\section{As parteiras}

Durante a análise dos resultados deste estudo será dada ênfase à teoria de Inglod (2010) sobre a noção de pessoa, onde se evidencia como esta se constrói. Conforme esse autor a pessoa se torna pessoa através do relacionamento com o mundo e com os outros, ou seja, o desenvolvimento das pessoas se dá na presença e contribuição de outras pessoas. Isso é notável na transmissão do conhecimento da arte de partejar, das parteiras experientes para às novas parteiras em Ribeira da Barca.

Inglod (2010) propõe o conceito de habilidades humanas como propriedades emergentes de sistemas dinâmicos, em que cada geração alcança e ultrapassa a sabedoria de seus predecessores. Conclui que, a contribuição que cada geração dá à seguinte para o aumento do conhecimento humano, se dá menos por um suprimento acumulado de representações e mais por uma educação da atenção. 
Essa transmissão de conhecimento de uma geração a outra geração é visível em Ribeira da Barca, onde as parteiras iniciam o ofício através do acompanhamento de parteiras experientes ou por transmissão de saberes de mãe para filhas. É notável a preocupação das parteiras em transmitir esse saber, de geração em geração, de forma a dar continuidade ao ofício. Vê-se o caso da Dona Mira, de 70 anos de idade, que desde quando era jovem faz partos. Começou o ofício de parteira porque a tia lhe incentivava a acompanhá-la e lhe dizia que tinha de passar essa experiência a alguém e que essa pessoa seria a Dona Mira. A primeira vez que acompanhou a tia, disse que sentiu medo porque lhe mandava fazer coisas como "cortar o umbigo", ela não sabia como fazer, e a tia the ordenava "faça" e depois "banha a criança". Inicialmente, ficou admirada com a postura da tia, mas foi-se acostumando e, pouco a pouco, foi ganhando prática.

Há uma necessidade premente das parteiras passarem o conhecimento para as mais novas, para que esse ofício se persiste ao longo dos tempos, de forma a apoiarem as futuras mães na hora do parto, como refere Teixeira (2011):

As parteiras tradicionais são mulheres que se dedicaram ao ofício de assistir à futura mãe na hora do parto. Possuem um conhecimento prático e empírico sobre a arte de amparar a mãe e o bebê no momento do nascimento, prestando cuidado e dedicação. O saber das parteiras está guardado na memória e nas histórias, que serão contadas, repassadas e que fazem parte do interesse e do imaginário da comunidade, falando da chegada de cada novo filho. (Teixeira, 2011, p. 2)

As parteiras de Ribeira da Barca demonstram ser muito dedicadas aos seus ofícios. Mesmo sem nenhuma remuneração, elas fazem de tudo para realizarem, com dedicação e prudência, os partos, sempre que forem chamadas. Conforme a Dona Mira, sempre que era chamada deixava tudo aquilo que estava a fazer, se estivesse a comer deixaria de comer, se estivesse a cozinhar chamava a vizinha para terminar, e saia logo para fazer o parto.

Para além de assistirem a mulher durante o trabalho de parto, as parteiras tratam do curativo do umbigo do bebé, em casos de doença auxiliam as famílias, receitando remédios caseiros e chás, e na morte, na preparação do corpo. Elas têm um importante papel no atendimento à saúde materna e infantil na sua localidade.

Já fiz vários partos de 7 meses, e num deles, o bebé nasceu com $750 \mathrm{~g}$, cuidei dele curando-lhe umbigo e dando-lhe banho até completar um mês. Depois de a banhar, a mãe da criança fazia uma cama de lençol bem quentinha onde a colocava. Depois de um mês a criança apanhou peso e ninguém a reconhecia. (D. Mira, 70 anos) 
As parteiras normalmente têm um bom relacionamento com a comunidade e são tratadas com muito carinho, como se fossem membros de uma grande família, quer pelas mães, como pelas crianças e pelos jovens que nasceram pelas suas mãos.

As dificuldades apontadas pelas parteiras no trabalho de parto são, na sua maioria, relacionadas com a saída da placenta. D. Filó, uma dessas parteiras, afirmou que teve problemas com a saída da placenta e acrescentou que, nesses casos, a parteira faz massagem esforçada no ventre da mulher para a ajudar e facilitar a descida da placenta. Explica também que, caso demorar mais de 1 hora para sair, ela manda a parturiente para o hospital.

A seguir serão discutidas e analisadas as técnicas utilizadas pelas parteiras antes do parto, durante o parto e no pós-parto.

\section{As técnicas do parto}

A análise das técnicas utilizadas pelas parteiras em Ribeira da Barca também se sustenta na teoria defendida por Inglod (2012), onde afirma que a forma é o fim e o dar forma é movimentação, ação. Dar forma é dar vida. Isso é notável nas técnicas que as parteiras usam no tratamento e cuidado, no moldar do corpo da mulher durante a gravidez, no parto e pós-parto, mas também no moldar do corpo da criança, logo após o nascimento.

Em Ribeira da Barca, a população é externamente pobre, vivendo da pesca e da apanha de areia, quando a natureza a permitir. A comunidade conta com um posto sanitário com acesso aos cuidados básicos, mas caso houver alguma situação de difícil controlo por parte do profissional do posto, por falta de condições mínimas, tem que se percorrer cerca de $12 \mathrm{~km}$ até o Hospital Regional Santiago Norte, em Santa Catarina. No caso de a deslocação ocorrer durante o dia é sempre mais fácil porque as pessoas poderão utilizar o transporte público, neste caso os hiaces, ${ }^{2}$ mas se for à noite tem de se alugar uma viatura particular pelo valor de dois mil, setecentos e cinquenta escudos cabo-verdianos (2750\$00), o equivalente a 25 euros, para irem ao Hospital.

As mulheres, muitas vezes, preferem as parteiras tradicionais por se sentirem mais seguras, pois, com elas têm mais intimidade e, na maioria das vezes, são suas comadres, tias ou amigas. As parteiras têm um papel fundamental no apoio às futuras mães e à comunidade em si. Em Ribeira da Barca, as parteiras, as ajudarem dispõem de técnicas próprias de apoio às grávidas durante a gestação, no parto e no pós-parto. A partir dos seis meses

\footnotetext{
${ }^{2}$ Hiaces, como são chamados em Cabo Verde, são os carros utilizados para o transporte público entre regiões. Esta denominação é uma referência ao modelo do veículo.
} 
de gestão da mulher, começam a ter um papel preponderante na preparação do corpo da mulher para o parto, inicialmente com massagens no ventre para evitar estrias e, em casos específicos, para endireitar a criança no ventre. ${ }^{3}$ Com a dilatação do ventre, para evitar que a pele da barriga da grávida rasgue e provoque estrias, a parteira coloca azeite de purga ${ }^{4}$ suficiente nas mãos e faz massagem no ventre da mulher. Essa técnica é chamada pelas parteiras, em Crioulo cabo-verdiano (a língua materna), de compu barriga ${ }^{5}$ Essa massagem não é feita apenas para prevenir as estrias, mas também para endireitar $a$ criança e colocá-la na posição apropriada para o nascimento e, no pós-parto, é feita para facilitar a saída da placenta.

Antes do parto, quando a mulher sente que a criança não está direita [na posição que deve estar], manda-se-me chamar e, quando lá chego, coloco "azeite de purga" nas mãos, esquento as mãos num candeeiro e faço massagem na barriga da mulher para endireitar a criança caso estiver de lado, de pé, para virá-la de forma a ir para o "nascedor". (D. Filó, 50 anos)

Essa mesma técnica é referida por Fleischer (2007) no seu trabalho sobre parteiras, buchudas e aperreios, realizada na cidade de Melgaço, em Belém do Pará, no Brasil. Nessa cidade essa técnica é denominada puxação. Consiste em puxar a barriga para se saber se o bebé está na posição certa, ou seja, na posição cefálica. Essa massagem é feita durante toda a gravidez e no pós-parto. Durante a gravidez essa técnica é utilizada para facilitar o parto vaginal, evitar o toque vaginal que tanto as mulheres reprovam, e no pós-parto:

Puxa-se a barriga da parturiente quando a placenta resiste em desocupar, isto é, descolar-se das paredes do útero e ser parida. Aqui, a puxação é mais um dos artifícios usados para a saída da placenta, um momento cheio de ansiedade para as parteiras. (Fleisher, 2007, p. 140)

Em Ribeira da Barca, aos nove meses de gestação a mulher prepara-se para o parto. Ela prepara um banho de palha de banana seca ou de tamarindo.

\footnotetext{
${ }^{3}$ Endireitar a criança no ventre é colocá-la na posição cefálica.

${ }^{4}$ Azeite de Purga é derivado da semente de purgueira, planta da família das Euforbiáceas, também chamada pinheiro-de-purga, cujas sementes produzem um óleo fortemente purgativo, usado também na iluminação e conhecido por azeite de purgueira.

${ }^{5}$ Compu Bariga é a massagem feita com azeite de purga para evitar estrias durante a gravidez e, também, para endireitar a criança no ventre quando não se encontra na posição cefálica. No pós-parto é feita massagem no ventre da mulher com azeite de purga para facilitar a saída da placenta.
} 
Primeiramente ferve a palha de banana ou de tamarindo numa panela com água. Conforme a Dona Antónia, uma das parteiras dessa localidade, esse líquido não é para beber, porque senão, como diz, antecipa o parto. É colocado numa banheira ou numa bacia de cama e a mulher, em pé, banha-se da cintura para baixo. Segundo a Dona Antónia, isso é para tirar frieza e provocar bastante urina. Isso faz com que, na hora do parto, a bolsa de água não tenha muito líquido. Outras mulheres que ela já assistiu em trabalho de parto, em vez de a bolsa de água se arrebentar, elas sentem vómitos no momento do parto.

A técnica do banho de assento é muito utilizada pelas parteiras tradicionais, não só em Cabo Verde, mas em várias paragens do mundo. Alguns autores referem-se a essa técnica nos seus estudos sobre o assunto. É o caso do estudo realizado por Sousa (2000) junto a parteiras no sertão do Ceará, no Brasil, onde refere que

Tradicionalmente os saberes das parteiras sobre os banhos de assento, as massagens, puxações, com ervas, folhas e cascas para o corpo e para cabeça constituem-se em fator preponderante. Segundo elas, assim o mal é dissipado através das "puxangarias", o corpo da mulher ganha mais expressão e, portanto, se torna mais saudável. O contato e aproximação física entre parturiente e parteira reconstituem a solidariedade. O tocar, o apalpar, sentir o corpo, se opõe a medicina formal que faz intervir a mediação instrumental e a distância social. (Sousa, 2000, p. 156)

Antes de iniciar o processo do parto, a parteira pergunta à mulher se não tem pressão alta ou outras complicações, e caso não as tiver inicia-se o parto, senão é encaminhada ao hospital. Na hora certa de se fazer o parto ou momento da nascença do bebé, segundo a Dona Filó, é vista a diantera, ou seja a bolsa de água se arrebenta.

O material normalmente utilizado pelas parteiras para realização do parto, na comunidade de Ribeira da Barca, é a tesoura, compressa, álcool e linha para amarrar umbigo (normalmente é a linha de croché que se trança para ficar mais forte e grossa) e água quente. Algumas parteiras, em vez da tesoura, usam uma lâmina nova.

\section{Trabalho de parto}

A parteira é sempre acompanhada por outra mulher que lhe ajuda durante o parto. Essa mulher tem de ser uma pessoa calma porque o parto exige cuidados, serenidade e perseverança. Nos partos domiciliares, em Ribeira da Barca, há o costume, muito forte, de se rezar antes do parto, em que a parteira benze e faz uma oração, dizendo: 
Meu Deus! Entrego tudo em suas mãos. Seja o que Deus quiser; Deposito a minha confiança em ti; Nossa Senhora do Parto me ajude!

A parteira, a ajudante e a parturiente rezam uma Ave-Maria em voz alta e, durante o parto, somente a parteira reza em silêncio. Dona Filó refere que, normalmente, quando faz um parto, antes de o iniciar, pede a nossa Senhora de Bom Parto que a ajude, para que tudo corra bem. Toda a oração a volta do trabalho de parto tem a ver com a delicadeza deste momento difícil para muitas mulheres, porque não se pode determinar o desfecho da situação, que poderá ser bom, ou não, para mulher e o bebé. Por isso, esse recorrer à Nossa Senhora do Bom Parto e à Virgem Maria para se amparar neste momento delicado e trazer um pouco de confiança e segurança durante todo o trabalho de parto.

Antes do parto, prepara-se a cama com uma coberta ou um lençol, sendo que, por baixo, é estendido um plástico grande para impedir que o colchão fique manchado. A mulher deita-se em cima da cama e a parteira ajoelha-se à sua frente. Coloca-se em baixo das nádegas da parturiente uma ordidja, que é feita com um lençol ou uma toalha de banho, que é enrolada em forma de círculo fechado, isso para permitir que a criança saia pela vagina em vez de dirigir-se para o ânus. A parturiente coloca as mãos em cada um dos joelhos para fazer força. Logo que se vê a cabeça da criança, a mulher dá o impú, que significa fazer força para expulsar o bebé, ou seja, é o período expulsivo. A parteira coloca dois dedos na parte inferior da vagina para facilitar a saída do bebé e para evitar lacerações na vagina. Logo que a criança saia é embrulhada num lençol e é colocada entre as pernas da mãe para se a manter bem quentinha e, assim, a parteira finaliza os cuidados a se ter com a mãe. Como última fase do parto, faz-se a massagem no ventre da mãe para permitir a saída da placenta. Caso houver dificuldades na sua saída há três técnicas que podem ser utilizadas, a saber: o uso de uma colher, soprar numa garrafa ou quebrar um ovo na boca da mulher. Esses materiais são utilizados porque do uso quotidiano pelas mulheres e de fácil acesso.

Primeiramente coloca-se na boca da mulher uma colher, logo ela sente vontade de vomitar e faz força para cima e a placenta sai. Uma outra forma é dar uma garrafa à mulher e lhe pedir que a sopre com força e, com esse esforço, a placenta cai. Pode-se também quebrar um ovo na boca da mulher que, ao sentir "ânsia de vómito" (vontade de vomitar), provoca a saída da placenta. (D. Antónia, Parteira)

Segundo a Dona Mira, logo que começa a sair, amarra-se a placenta na perna da parturiente para não entrar de novo no seu corpo, porque senão lhe 
dá muito trabalho fazê-la sair, e também pode provocar sangramento. Depois, lava-se a mulher com água quente e sabão e deixa-a limpa, e logo em seguida vai-se cuidar do bebé. A finalidade que se dá à placenta, conforme algumas parteiras, é enterrá-la num buraco fundo, de preferência em baixo da pedra de fogão de lenha. Isso, segundo afirmam, é para evitar que a mulher não sinta dores de barriga. Mas para outras parteiras, como a Dona Filó, a placenta deve ser enterrada, de preferência, num lugar muito distante da casa para não ser desenterrada por animais e não incomodar a população por causa do mau cheiro.

Outra forma de realizar o parto é ficar de joelhos. Põe-se um lençol no chão e a mulher nele se ajoelha. A parteira senta-se no chão, em frente à parturiente, e estica as duas pernas. Uma das pernas da parteira serve de suporte para que a parturiente possa sentar em cima e ajudá-la a susti cento, ou seja, apoiar o ânus. A Dona Filó confessa não gostar muito de realizar parto de joelhos porque é sempre mais cansativo para a parteira e para a mãe, mas diz que já fez alguns desses partos, em que a mulher se põe de joelhos, a parteira coloca um pano no chão, para proteger o bebé ao nascer, de modo a não bater no chão. Enquanto a mulher se encontrar de joelhos a parteira ajuda-a, fazendo esforço na barriga. Salienta que, às vezes, nesse tipo de parto dava complicações porque a criança tem tendência de ir para centu, ou seja, para o ânus, e quando assim acontece a ajudante segura-o forte, com um pano, de forma que a criança fique não posição correta de nascer.

Também o parto pode ser feito num banquinho, onde se coloca uma ordidja para a mulher se sentar e susti cento. A parteira fica em frente para amparar a criança. Essas duas últimas formas, segundo a Dona Antónia, facilitam mais o parto do que em cima da cama.

Durante o trabalho de parto, a mãe da parturiente fica a dar as providências, ou seja, prepara a refeição própria para essa ocasião, que é canja de galinha ou então café, todos eles acompanhados de manteiga de terra. ${ }^{6}$ Há mulheres que, logo a seguir ao parto, tomam uma xícara de café com manteiga de terra para repor as forças.

Conforme as parteiras, o marido, normalmente, fica impaciente e prefere sair de casa e só volta depois do parto finalizado. Essa impaciência do marido é algo que é-lhe transmitido, devido à gravidade que poderá ser um trabalho de parto, pelas pessoas que estão envolvidos neste processo. Normalmente essas pessoas deixam o marido saber que, naquele momento, não deve estar presente, que a sua presença só atrapalha.

\footnotetext{
${ }^{6}$ Manteiga terra é manteiga caseira produzida do leite de vaca.
} 


\section{O pós-parto}

Durante a gravidez a mulher, normalmente, prepara uma faixa feita de tecido branco que será utilizada logo a seguir ao parto para apertar barriga, isto é, para facilitar que o útero vá para o lugar rapidamente e para que a mulher não fique com o ventre grande.

Durante uma semana, a mulher lava-se com água de folha de purga. ${ }^{7}$ Para isso, lava-se a folha de purga bem limpa e depois é colocada numa panela com água a ferver. Depois de fervida é posta numa bacia limpa, a mulher senta-se em cima e passa uma toalha em volta para não permitir que o vapor se desvaneça. Ao tomar esse vapor irá permitir a saída do sangue acumulado no útero. Essa técnica é chamada de fitcha corpo. ${ }^{8}$ Ainda ao tomar este vapor irá permitir a cicatrização do corte ou lacerações na vagina durante o parto.

$\mathrm{Na}$ verdade o banho que elas passavam trinta dias para tomar era o banho com água fria e quando se molhava a cabeça. A orientação dada por todas as parteiras, entretanto, era a de que a região genital fosse lavada várias vezes ao dia com água morna e, pelo menos, uma vez por dia, as mulheres tomassem um meio banho. Muitas vezes esse meio banho deveria ser feito com o cozimento da raiz de aroeira, que era uma forma de prevenir infeções. (Sousa, 2000, p. 184)

Para tirar todo o sangue de dentro, como refere D. Filó, a mulher tem que beber um copo de água de folha de purga fervida, a fim de se libertar de todo o sangue que tem dentro, e isso ajuda o útero a ir para o lugar. Quando a mulher bebe uma chávena desse líquido fica com o ventre pequeno. Ao se dar o chá para permitir que o útero vá para o lugar, podemos compreender que o corpo e a sua forma não são algo dados como definitivos, pré-determinados. Que este processo tem vida e que se pode dar forma ao corpo da mulher no pós-parto, ou seja, esse processo não é mais do que um processo de recomposição. Este processo, como refere Inglod (2012), é um processo de formação ao invés de um produto final, no sentido em que a "forma" é algo morto, final, sem vida, enquanto o "dar forma" é vida, movimentação, ação.

A atuação das parteiras, as técnicas que utilizam para endireitar a criança no ventre, de compu barriga, de fitcha corpo, demonstram que o nosso corpo

\footnotetext{
${ }^{7}$ Folha de purga, folha da planta purgueira referida anteriormente.

${ }^{8}$ Fitcha Corpo é uma técnica utilizada no pós-parto para facilitar que o útero vá para o lugar. Além do banho de assento, é feita também uma massagem no ventre com azeite de purgueira; preparase chá de folha de purgueira que é tomado para facilitar a saída do sangue nos pós-parto; também para isso utiliza-se uma faixa para apertar o ventre. Todo esse processo chama-se fitcha corpo.
} 
não nos é dado na sua forma definitiva, acabada, que se pode lhe dar forma e, esse dar forma, é dar vida. Essa interação das parteiras com o corpo da mulher é pelo facto de que há uma relação entre a matéria e a força, num mundo onde há vida, onde tudo pode se transformar.

O azeite de purga é utilizado essencialmente na gravidez, parto, pós-parto e no cuidar dos bebés. Normalmente, quem ajuda a mulher depois do parto, no período de resguardo (para não apanhar frieza e outras doenças), que vai até um mês, é a sua mãe, sua irmã, mas caso nenhuma delas viverem próximas pode ser a cunhada ou uma vizinha. Alguns maridos, como é o caso do marido da D. Filó, referem que, durante o resguardo das suas mulheres, faziam tudo em casa, desde lavar a roupa, cozinhar, limpar a casa, engomar, etc. Esse mesmo procedimento é referido por Sousa (2000), ao afirmar que:

Era muito comum que, quando estivesse perto do parto, uma mulher de sua família viesse para sua casa para assumir seu lugar no comando da casa: uma prima, uma irmã solteira, uma tia, a mãe, a sogra, a cunhada. Estas mulheres vinham e passavam todo o mês de resguardo, não só fazendo todas as tarefas da casa como ainda ajudando a cuidar da mulher de resguardo e do bebê. Este procedimento só não era necessário caso a parturiente morasse com a mãe, com a sogra ou ela já tivesse filhas em idade de assumir o comando da casa no lugar da mãe. (Sousa, 2000, p. 189)

Dona Filó disse que faz o resguardo, passando quatro dias na cama e os restantes dias passa-os em casa fazendo serviços leves e, sendo que no final do dia, usa sempre um casaco e coloca $s u l a d a^{9}$ na cintura para proteger a barriga, não sai de casa para não apanhar frieza. Como salienta Sousa (2000):

Primeiro, a ideia de que as mulheres deveriam ficar de repouso absoluto durante oito dias, ou seja, até a queda do umbigo do bebê, as mulheres deveriam só levantar-se para comer e para fazer seu asseio. A parteira faz referência ao costume de se tampar os ouvidos das mulheres e de elas calçarem meias durante o resguardo. As mulheres tampavam os ouvidos para abafar os possíveis barulhos da casa. As relações sexuais com o marido também estavam interditadas durante cerca de 30 ou 40 dias, dependendo da dificuldade do parto. (Sousa, 2000, p. 187)

Esse período de resguardo vai de uma semana a um mês, conforme as necessidades financeiras da mulher.

\footnotetext{
${ }_{9}$ Sulada, expressão utilizada para designar o pano, faixa de pano que é amarrada por cima das coxas.
} 


\section{Cuidar do bebé}

A parteira, para cortar o umbigo do bebé, mede, a partir do umbigo, uma palma do cordão umbilical. Dessa palma, corta apenas a metade. Logo que se corta o umbigo tira-se todo o líquido que se encontra dentro do cordão umbilical, depois passa-o por álcool e embrulha-o numa compressa. Conforme a Dona Antónia, não se deve deixar que o álcool caia no ventre do bebé para que não se queime. Depois enrola-se a compressa no ventre da criança para proteger o umbigo e para evitar que tenha infeção. Nesse dia a criança não é banhada, é apenas limpa com um pano húmido e amarrada a cabeça com um pequeno lenço para compor a cabeça e para que a mesma fique bonita.

O umbigo da criança é guardado num pano branco e limpo. Segundo ainda a Dona Antónia há pessoas que guardam o umbigo da criança para, em caso de dores de barriga, ferve-lo em água e dá-la de beber à criança. Quando se banha a criança deve-se ter o cuidado com o umbigo, ou seja, secá-lo bem para não infetar e queimá-lo com álcool. Logo que o umbigo cai é-lhe colocado tabaco ou cancan $^{10}$ para ajudar a cicatrizar a pequena ferida que permanece. Algumas parteiras, para fazerem o curativo no umbigo do recém-nascido, usavam o álcool, a tintura e, às vezes, antisséptico. ${ }^{11}$ Outras preferem utilizar um pano embebido em azeite de purga esquentado ao lume, e queimava-o. Quando o umbigo cai, coloca-se tabaco e o amarra-se.

Para tirar basga ou catarro acumulado no peito do bebé é preparado o chá de alecrim ou alfazema.

Não se ferve a erva, apenas água que depois é colocada numa chávena e junta-se-lhe a erva. Logo que a erva se desbote e o chá fique com a cor verde, é dada à criança e, imediatamente, ela vomita e tira todo o catarro que tem no peito. (D. Antónia)

Para evitar dores de barriga no bebé, durante os três primeiros meses, faz-se fumador de alfazema e passa-se uma fralda de pano, nesses fumadores, e depois coloca-se no ventre do bebé para facilitar a saída de gazes. Para o mesmo efeito, é utilizado o azeite de purga. Passa-se um pouco de azeite de purga nas mãos, põe-se as mãos em volta de uma vela acesa ou de um candeeiro para aquecer o azeite e faz-se massagem no ventre do bebé.

\footnotetext{
${ }^{10}$ Tabaco de folha de louro.

${ }^{11}$ Anti-séptico eficiente para uso tópico, com efeito antimicrobiano. Serve para desinfeção e higiene da pele e mucosas em primeiros socorros etc.
} 
Quando a criança sente dores de barriga, apanho uma fralda de pano, aqueço-o num candeeiro, e coloco-o na barriga da criança, ou sopro o umbigo do bebé e coloco tabaco de folha de louro. (D. Filó, 50 anos)

Utiliza-se o mesmo processo para ajudar a compor a vagina de uma bebé, vagina considerada descomposta ou screpo. Faz-se a massagem de fora para dentro com azeite de purga morna até que a vagina fique fechada e bem composta. Também para compu nariz. ${ }^{12}$ ou filar o nariz que nasce um pouco abatatado, coloca-se azeite de purga nas mãos e faz-se massagem no nariz, porque se considera que o nariz filado é bonito, para o mesmo efeito, também, coloca-se uma covinha em ambas as bochechas da bebé menina. Para subir os testículos dos bebés rapazes usa-se também a massagem com azeite de purga morna. Há criança que nasce com ânus fechado ou ânus imperfurado, neste caso utiliza-se a técnica de abertura de ânus. Esta técnica consiste na colocação do azeite de purga no dedo mindinho ou no quinto dedo para o abrir. Isto acontece excecionalmente. Todo esse processo de compu vagina, compu nariz, entre outros, como visto anteriormente, são processos de dar vida e dar forma às coisas, aqui vistas como "acontecer, ou melhor, um lugar onde vários aconteceres se entrelaçam" (Inglod, 2012, p. 27). Isso põe em causa, como refere o autor, a ontologia do pensamento ocidental em que o objeto é visto como o fim, como algo morto, sem vida e a forma como algo dado, definitivo.

$\mathrm{Na}$ história subsequente do pensamento ocidental, esse modelo hilemórfico da criação arraigou-se ainda mais, mas também se desequilibrou. A forma passou a ser vista como imposta por um agente com um determinado fim ou objeto em mente sobre uma matéria passiva e inerte. (Inglod, 2012, p. 26)

Por isso, Inglod desafia a noção estabelecida de "objeto" e propõe a noção de coisa, como algo dinâmico e como fluxos vitais, integrada aos ciclos da vida e ao ambiente. Todas as técnicas, acima referidas, estão intimamente relacionadas com a conceção de pessoa em Ribeira da Barca, onde a pessoa se constrói no relacionando com o mundo e com os outros.

\section{Conceção de pessoa na Ribeira da Barca}

Em Ribeira da Barca se constrói a noção de pessoa tendo em conta a relação da pessoa com a natureza e da natureza consigo mesmo. Não existe uma

${ }^{12}$ Compu Nariz significa filar o nariz, é feito logo após o nascimento do bebé. É colocado azeite de purgueira nas mãos, depois é passada a mão por cima de um candeeiro e faz-se massagem ao nariz de baixo para cima. 
fronteira visível entre eles e a própria natureza, tudo se mescla. Isso é notável na forma como as parteiras aprenderam o ofício, na maneira como moldam o corpo da mulher durante a gravidez, o parto e o pós-parto, no compu barriga, fitcha corpo, na alimentação própria no pós-parto, no resguardo, na maneira como trabalham o corpo da criança, compu nariz, compu vagina etc.

Para melhor compreensão da noção de pessoa é importante entender o debate que vem sendo feito em várias escolas de antropologia. Esse debate tem dividido pontos de vista de vários autores. Com o Iluminismo, no século 17 , e a tomada da razão como centro de tudo, na assim chamada racionalidade científica, o paradigma newtoniano-cartesiano teve como característica essencial a separação entre mente/corpo, sujeito/objeto, ser humano/natureza, razão/intuição. Muitos antropólogos analisaram a noção de pessoa com base na separação entre natureza e cultura, como Mauss (2003), Mead (1988), LeviStrauss (1976) e Geertz (1989). Na pós-modernidade surgem autores que põem fim a essa separação, como o caso de Inglod (1996), Latour (1994) e Strathern (1998). Primeiramente, o debate aqui proposto centra-se sobre esses autores, mostrando as suas linhas de pensamentos, para depois situar em quais dessas linhas pode ser enquadrada a discussão sobre a noção de pessoa em Ribeira da Barca.

Na maioria das vezes, se iniciam esse debate analisando a obra de Marcel Mauss, Categoria do espírito humano a noção de "eu". Nesta obra o autor analisa, primeiramente, a caracterização da pessoa nas sociedades primitivas e, posteriormente, constrói uma história social da noção de pessoa no Ocidente. Nas "sociedades primitivas" Mauss vai mostrar uma "[...] série das formas que esse conceito assumiu na vida dos homens, das sociedades, com base em seus direitos, suas religiões, seus costumes, suas estruturas sociais e suas mentalidades" (Mauss, 2003a, p. 371). Especificando o caso dos Pueblos, a noção de pessoa era confundida com o seu clã, ou seja, ela representaria não mais do que uma entidade social.

[...] Uma noção de pessoa, do individuo confundido com seu clã, mas já destacado dele no cerimonial, pela máscara, por seu titulo, sua posição, seu papel, sua propriedade, sua sobrevivência e seu reaparecimento na terra num de seus descendentes dotado das mesmas posições, prenomes, títulos, direitos e funções; (Mauss, 2003a, p. 375)

Para demonstrar como a noção de pessoa se constrói socialmente, através de toda uma pedagogia técnica e simbólica que institui o sentido do corpo, é importante referir a obra As Técnicas Corporais, do mesmo autor, na qual 
ele salienta as técnicas que definem o uso que fazemos do nosso corpo, seja andar, nadar, correr, comer, como sendo pré-estabelecidas socialmente. Ele entende como técnicas corporais "as maneiras como os homens, sociedade por sociedade, e de maneira tradicional, sabem servir-se de seus corpos" (Mauss, 2003b, p. 211). A maneira como dormimos, comemos, os movimentos corporais no geral, são apreendidos culturalmente por meio da educação técnica. Mauss refere que essas técnicas são atos tradicionais e eficazes, porque para haver técnicas essas têm de ser tradicionalmente transmitidas, ou seja, têm de ser estabelecidas culturalmente dentro de um grupo de indivíduos.

É importante incluir neste debate Tim Inglod (1996, 2010 e 2012), para compreender outra forma de pensar a noção de pessoa. O autor pretende superar a dualidade mente-corpo, natureza e cultura que até então era central no pensamento Ocidental, onde se conciliava o biológico individual e uma tendência cultural coletiva e propõe uma totalidade indivisível entre organismo e ambiente. Segundo Silva (2011), a proposta deste autor apresenta

desafios direcionados à antropologia cultural e à ciência biológica, pois concebe um mútuo envolvimento entre cultura e natureza e entre pessoas e organismos que, em sinergia, dão lugar à ação e à consciência dentro de um processo contínuo da vida. (Silva, 2011, p. 358)

Esse dualismo mente-corpo é notável na ciência cognitiva onde se argumenta que "o conhecimento existe sobre a forma de conteúdo mental, que, com vazamentos e preenchimento pela margem, é passado de geração em geração, como herança de uma população portadora da cultura" (Inglod, 2010, p. 6). O defensor dessa ideia é o antropólogo Dan Sperber que, segundo Inglod, defende uma "epidemiologia de representações". Sugere que "toda a representação existe ao nível de realidade concreta com a população de suas ocorrências, sejam estas encontradas dentro de cérebros humanos ou no comportamento corporal que desencadeiam" (Inglod, 2010, p. 7). Tal divisão, naturalizada como diferença, foi elevada a um princípio fundador da sociologia do conhecimento, aparecendo em dois níveis. O primeiro nível dessa partilha, externo, corresponde à divisão entre Nós (ocidentais) e Eles (não ocidentais) e o segundo, interno, é a partição entre a natureza e a cultura do Nós e a imbricação cultura e natureza do Eles (Latour, 1994, p. 98).

Tim Inglod (1996, 2010,2012) traz uma nova abordagem, na qual questiona toda a epistemologia do pensamento antropológico tradicional, propondo uma totalidade indivisível, onde tornar-se pessoa é um processo de tornar-se um 
organismo, ou seja, para ele há um contínuo entre a cultura e natureza. Para o autor, as capacidades de pensar e agir surgem como propriedades emergentes de todo um sistema total de desenvolvimento constituído por meio da disposição da pessoa para estar, desde o princípio, dentro de um campo de relacionamentos com o mundo e com outras pessoas (Silva, 2011).

Introduzindo a noção de pessoa em Ribeira Barca, é importante refletir sobre o papel das parteiras neste processo de constituição de pessoa. As parteiras aprenderam o ofício acompanhando outras parteiras e servindo de ajudante durante todo o processo do parto. Essa aprendizagem, como muitos pensam, não é transmitida pacificamente de geração em geração. As parteiras no seu ofício alcançam e ultrapassam a sabedoria da sua antecessora, como refere Ingold (2010). Por isso, ele refere que o conhecimento consiste em habilidades. Isso significa que a parteira tenha de interagir com o ambiente circundante no fazer, aprender a arte e a técnica do partejar. Cada vez que intervenha pode atingir outro patamar de conhecimento. Nesse sentido, só com a receita pronta de como fazer um parto, e a possibilidade de possuir capacidade de apreensão, não serão suficientes efetivamente para serem boas parteiras.

Há uma intervenção das parteiras no moldar e no tratamento do corpo da mulher durante toda a gravidez, noparto e no pós-parto, no compu barriga, fitcha corpo, compu cabeça, compu vagina, fila nariz, ou seja, "no dar forma ao corpo e na sua própria recomposição (Inglod, 2012), que não é algo já dado, mas passa por transformações em todo o processo relacional de tornar-se pessoa. Tudo isso é essencial na forma como as pessoas se tornam pessoas em Ribeira da Barca, onde natureza e cultura se misturam, num ambiente onde há fluido de vida, onde nada é dado no seu aspeto final. As técnicas que são adquiridas culturalmente são aplicadas diretamente no corpo da mulher que leva à mudança na posição do bebé no ventre, e isso quer dizer que foi a própria exigência da natureza que influenciou a necessidade dessa aprendizagem, naquilo que é considerado cultural, ou seja, foi dada pela própria necessidade de interpretar a natureza. Não existe uma fronteira visível entre natureza e cultura e é notável no moldar do corpo, no controle da fertilidade, em todos aspetos do dia-a-dia, ou seja, no pautar do quotidiano.

É importante concluir que, em Ribeira da Barca, a noção de pessoa se constrói tendo em conta a relação da pessoa com a natureza e da natureza consigo mesmo. A pessoa só se torna pessoa dentro de um mundo de relacionamentos. Tudo isso implica a forma como as pessoas se constituem como pessoas, o que passa também pela relação e vínculo que as pessoas estabelecem entre si. 


\section{Conclusão}

Este trabalho é resultado de uma pesquisa de campo realizado em Ribeira da Barca, uma das localidades do Concelho de Santa Catarina de Santiago. Foi utilizado o método etnográfico por ser um trabalho que exigia retratar os pormenores do quotidiano, as coisas corriqueiras da vida, as observações de pessoas comuns em suas rotinas diárias, as conversas e convivências diárias com pessoas. Foi nesta experiência pessoal de meses de trabalho de campo que se baseou as reflexões, análise e produção do presente texto. Os trechos tirados dos diários de campo e dos cadernos de notas ajustam às estórias aqui contadas, principalmente para discutir com assuntos aqui apresentados como parteira, o partejar e a noção de pessoa. Por isso, de acordo com a análise resultado desta etnografia, conclui-se que em Ribeira da Barca não existe uma fronteira visível entre eles e a própria natureza, tudo se mistura. Isso é notável na forma como as parteiras aprenderam o ofício, na maneira como moldam o corpo da mulher durante a gravidez, no parto e no pós-parto, no compu barriga, no fitcha corpo.

Para dar mais realce, segundo Goldman (2006), hoje em dia, a antropologia está num patamar onde pensar o individuo como um ser dual onde há uma separação nítida entre o corpo e a mente, não seria adequado. Atualmente, essa discussão, como refere Goldman (1996), não passa de pura abstração porque a cultura investe diretamente no corpo.

Segundo Inglod (2012), o corpo é algo vivo e dinâmico, não é dado na sua forma definitiva, poderá ser moldado, pode passar por um processo de recomposição. A posição do autor é que a forma é o fim, a morte e o dar forma é movimento e vida, ação. Isso quer dizer que ele põe em causa o facto de que o corpo é dado na sua forma definitiva, uma vez que está em constante interação com o ambiente; o corpo é dinâmico, passa pelo processo de lhe ser dado forma, de ser recomposto. Também, o autor põe em causa toda a ontologia Ocidental proposta desde Aristóteles sobre a forma e a matéria, um modelo hilemórfico de criação, onde a matéria e a forma constituíam os dois princípios fundamentais de todos os seres da realidade, inclusive a alma, que possuiria esses dois aspetos.

A partir deste referencial, esse estudo abre caminho para novas reflexões sobre o parto natural e as suas técnicas e também sobre as novas formas de pensar o individuo no campo da antropologia.

\section{Referências}

DAMATTA, Roberto. Relativizando: uma introdução à antropologia social. Petrópolis: Editora Vozes, 1981. 
FAVRET-SAADA, de Jeanne. Ser afetado. Cadernos de Campo, v. 13, p. 155-161, 2005.

FLEISCHER, Soraya R. Parteiras, buchudas e aperreios na etnografia do atendimento obstétrico não oficial na cidade de a Pará. Porto Alegre, 2007. Tese de doutorado em Antropologia, Programa de Pós-graduação em Antropologia Social, Universidade Federal do Rio Grande do Sul.

GEERTZ, Clifford. A interpretação das culturas. Rio de Janeiro: Editora LTC, 1989.

GOLDMAN, Márcio. Uma categoria do pensamento antropológico: a noção de pessoa. Revista de Antropologia, v. 39, n. 1, p. 83-109, 1996.

INGOLD, Tim. Human worlds are culturally constructed: against the motion (I). In: Tim Ingold (Org.). Key debates in anthropology. London: Routledge, 1996. p. 81-119.

INGOLD, Tim. Da transmissão de representações à educação da atenção. Educação, v. 33, n. 1, p. 6-25, 2010.

INGOLD, Tim. Trazendo as coisas de volta à vida: emaranhados criativos num mundo de materiais. Horizontes Antropológicos, v. 18, n. 37, p. 25-44, 2012.

LATOUR, Bruno. Jamais fomos modernos. Rio de Janeiro: Ed. 34, 1994.

LÉVI-STRAUSS, Claude. As estruturas elementares do parentesco. Petrópolis: Vozes, 1976.

MALINOWSKI, Bronislaw. Os argonautas do Pacífico Ocidental. São Paulo: Ed. Abril, 1978.

MEAD, Margaret. Sexo e temperamento. São Paulo: Perespectiva, 1988.

MAUSS, Marcel. Uma categoria do espírito humano: a noção de Pessoa, a noção do "Eu". In: Marcel Mauss. Sociologia e antropologia. São Paulo: Cosac \& Naify, 2003a.

MAUSS, Marcel. As técnicas do corpo. In: Marcel Mauss. Sociologia e antropologia. São Paulo: Cosac \& Naify, 2003b.

SILVA, Regina Coeli Machado. A teoria da pessoa de Tim Ingold: mudança ou continuidade nas representações ocidentais e nos conceitos antropológicos? Horizontes Antropológicos, v. 17, n. 35, p. 357-389, $2011<$ dx.doi.org/10.1590/S010471832011000100012>.

SOUSA, Noélia Alves de. Sábias mulheres: uma investigação de gênero sobre parteitas no sertão do Ceará (1960-2000). Rio de Janeiro, 2007. Tese de doutorado em História Social, Instituto de Filosofia e Ciências Sociais, Universidade Federal do Rio de Janeiro.

TEIXEIRA, Maria Verônica. Resgatando saberes: a cultura da parteira tradicional como estratégia de promoção da saúde. Salvador, 2011. Trabalho de conclusão de curso, Graduação em Psicologia, Centro Universitário Jorge Amado.

Recebido em: 25 maio 2014

Aprovado em: 15 jan. 2015

Autora correspondente:

Miriam Steffen Vieira

Rua Tomaz Flores, 235, ap. 201 - Bairro Morro do Espelho

93030-260 - São Leopoldo, RS 